\title{
Frequency of metabolic syndrome among newly detected type 2 diabetic patients with non-alcoholic fatty liver disease and high serum alanine aminotransferase levels
}

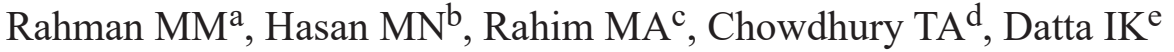

\begin{abstract}
Background: Non-alcoholic fatty liver disease (NAFLD) is emerging as one of the most common causes of chronic liver disease world-wide. It has strong association with obesity, type 2 diabetes mellitus (T2DM) and metabolic syndrome. We aimed to investigate the prevalence of metabolic syndrome in newly detected T2DM patients having NAFLD with high serum alanine aminotransferase (ALT) level.
\end{abstract}

Methods: In this cross-sectional study, 110 newly detected T2DM patients with high serum ALT level were evaluated. To find out the etiology of high serum ALT level, abdominal ultrasonography was done to detect NAFLD cases along with other relevant investigations. All NAFLD cases then underwent further evaluation for the prevalence of metabolic syndrome.

Results: Out of 110 study subjects, NAFLD was detected in 80 (72.7\%) individuals. According to International Diabetic Federation (IDF) criteria, metabolic syndrome was detected in 56 (56/80, 70\%) of NAFLD cases. Among the 56 patients with NAFLD, male were 24 (42.9\%) and female were 32 (57.1\%) and 14 (14/56, 25\%) cases had all five components of metabolic syndrome. Metabolic syndrome was found in all female NAFLD subjects $(32,100 \%)$. Mean age of patients with metabolic syndrome was 43.11 \pm 10.77 years and mean body mass index (BMI) was $27.87 \pm 3.72 \mathrm{~kg} / \mathrm{m}^{2}$. Hypertension was found in $37.5 \%$ cases. High BMI (e" $\left.25 \mathrm{~kg} / \mathrm{m}^{2}\right)$ was found in $87.5 \%$ cases. Mild, moderate and severe fatty liver were found in $28.6 \%, 46.4 \%$ and $25 \%$ cases respectively. Dyslipidemia was found in all (56, 100\%) NAFLD subjects with metabolic syndrome. Metabolic syndrome had significant correlation with BMI ( $p 0.00)$, abdominal obesity ( $p 0.00)$ and serum triglyceride level ( $p$ 0.04).

Conclusion: Over two-thirds of T2DM patients having NAFLD had metabolic syndrome in this study.

Key words: alanine aminotransferase, body mass index, non-alcoholic fatty liver disease, metabolic syndrome.

(BIRDEM Med J 2020; 10(1): 21-25)

Author information

a. Md. Mahbubur Rahman, Associate Professor, Department of Gastroenterology, Uttara Adhunik Medical College, Dhaka, Bangladesh.

b. Md. Nayeemul Hasan, Associate Professor, Department of Community Medicine, Uttara Adhunik Medical College, Dhaka, Bangladesh.

c. Muhammad Abdur Rahim, Associate Professor, Department of Nephrology, BIRDEM General Hospital, Dhaka, Bangladesh.

d. Tufayel Ahmed Chowdhury, Registrar, Department of Nephrology, BIRDEM General Hospital, Dhaka, Bangladesh.

e. Indrajit Kumar Datta, Associate Professor, Department of Gastroenterology, BIRDEM General Hospital, Dhaka, Bangladesh.

Address of correspondence: Md. Mahbubur Rahman, Associate Professor, Department of Gastroenterology, Uttara Adhunik Medical College, Dhaka, Bangladesh. Email: mahbuburrahmank47 @gmail.com

Received: May 4, 2019

Accepted: October 31, 2019

\section{Introduction}

Diabetes mellitus (DM) is a global public health issue. Patients with type 2 DM (T2DM) often have asymptomatic elevation of serum alanine aminotransferase (ALT) level. In the United States, nonalcoholic fatty liver disease (NAFLD) is replacing alcoholic hepatitis and viral hepatitis as the most common etiology of chronically elevated serum ALT in both diabetic and non-diabetic individuals. ${ }^{1}$ NAFLD is the most common cause of chronic liver disease in many developed countries ${ }^{2,3}$ and is closely associated with obesity $^{4}$ and cardiovascular diseases. ${ }^{5,6}$ Moreover, NAFLD has also been reported as risk factor, independent of the traditional risk factors, for subclinical atherosclerosis $^{7,8}, \mathrm{~T}^{2} \mathrm{DM}^{9}$ and increased mortality. ${ }^{10}$ Furthermore, NAFLD is expected to become an even 
more serious public health issue because of the increasing prevalence of obesity and aging. ${ }^{11,12}$ The presentation of the disease is mostly silent, considered as "silent liver disease". ${ }^{13}$ Approximately $10-25 \%$ of patients with "silent liver disease" develop non-alcoholic steatohepatitis (NASH) and 5-8\% of those will develop liver cirrhosis within 5 years. ${ }^{14}$

Metabolic syndrome is a cluster of metabolic abnormalities that is a precursor to cardiovascular disease, T2DM and chronic kidney disease. Patients with NAFLD are anticipated for the future development of the metabolic syndrome. Many cross-sectional studies have demonstrated that NAFLD is strongly associated with metabolic syndrome. ${ }^{15,16}$ So, NAFLD is often regarded as the hepatic component of the metabolic syndrome ${ }^{17}$ and makes the metabolic syndrome a relevant condition in clinical practice and a major public health concern worldwide. ${ }^{18-20}$ Nevertheless, very few studies were published internationally addressing specifically the prevalence of metabolic syndrome and associated factors in T2DM patients having NAFLD with raised serum ALT level. To the best of our knowledge, no study was done focusing this special issue in our country. So, we aimed to investigate the frequency of metabolic syndrome in this special group of patients.

\section{Methods}

In this cross-sectional study, 110 newly detected T2DM patients were selected at medicine outpatient department (MOPD) of Bangladesh Institute of Research and Rehabilitation in Diabetes, Endocrine and Metabolic Disorders (BIRDEM) General Hospital, Dhaka, Bangladesh, from August to October, 2009. Informed written consent was taken from every patient after explaining the purpose and procedure. A standard questionnaire was filled up. Every patient was evaluated clinically and supplemented by necessary laboratory investigations. Newly diagnosed, adult ( $\geq 18$ years), T2DM subjects with serum ALT $\geq 1.5$ times upper limit of normal were included in this study. Patients with history of regular alcohol intake more than 30 grams/ day in males and more than 20 grams/day in females, diagnosis of acute hepatitis/chronic liver disease, history of hepatotoxic drug intake were excluded. Anthropometric measurement included weight and height. Body mass index (BMI) was calculated as body weight in kilogram divided by height in meters square. Waist circumference was measured in $\mathrm{cm}$ at the horizontal plane mid-way between anterior superior iliac spine and lower costal margin at the narrowest part of the waist line while the patient was standing and at the end of normal expiration. Hip circumference was measured at a horizontal plane passed through the greater trochanter of femur on both sides in standing position. Hypertension was leveled with blood pressure $\geq 130 / 85 \mathrm{~mm} \mathrm{Hg}$ and/or on regular use of antihypertensive medication. Biochemical tests included oral glucose tolerance test (OGTT), fasting lipid profile, serum ALT level, viral markers like hepatitis B virus surface antigen (HBsAg) and antibody against hepatitis $\mathrm{C}$ virus (anti-HCV) and ultrasonography (USG) of hepatobiliary system and pancreas. Additional investigation was done as required.

Dyslipidaemia was defined according to National Cholesterol Education Programme (NCEP) Adult Treatment Panel (ATP) III Guideline: plasma triglyceride (TG) $\geq 150 \mathrm{mg} / \mathrm{dl}$, plasma total cholesterol $(\mathrm{TCH}) \geq 200 \mathrm{mg} / \mathrm{dl}$, plasma low density lipoprotein cholesterol (LDL-C) $>100 \mathrm{mg} / \mathrm{dl}$, plasma high density lipoprotein cholesterol (HDL-C) $<40 \mathrm{mg} / \mathrm{dl}$ in male or $<50 \mathrm{mg} / \mathrm{dl}$ in female.

Metabolic syndrome was defined according to International Diabetic Federation (IDF) criteria: central obesity (waist circumference $\geq 90 \mathrm{~cm}$ for male and $\geq 80$ $\mathrm{cm}$ for female as for Asian-Indian) plus any two of the following four criteria: (1) raised plasma TG level $\geq 150$ $\mathrm{mg} / \mathrm{dl}$ or $\geq 1.7 \mathrm{mmol} / \mathrm{L}$ or specific treatment for this lipid abnormality, (2) low plasma HDL-C $<40 \mathrm{mg} / \mathrm{dl}$ or $<1.03$ $\mathrm{mmol} / \mathrm{L}$ for males or $<50 \mathrm{mg} / \mathrm{dl}$ or $<1.29 \mathrm{mmol} / \mathrm{L}$ for females or specific treatment for this lipid abnormality, (3) high blood pressure (BP): systolic BP $\geq 130 \mathrm{~mm} \mathrm{Hg}$ or diastolic $\mathrm{BP} \geq 85 \mathrm{~mm} \mathrm{Hg}$ and (4) fasting plasma glucose $\geq 5.6 \mathrm{mmol} / \mathrm{L}$ or $100 \mathrm{mg} / \mathrm{dl}$ or use of medication for hyperglycemia. Abdominal USG was performed in a fasting state for at least 8 hours by a single sonographer using SIEMENS Sonoline Antares. NAFLD was classified according to the standard criteria accepted by American Gastroenterology Association (AGA) as follows: grade-1 (mild steatosis) - slight diffuse increase in the fine echoes in the hepatic parenchyma with normal visualization of diaphragm and intrahepatic vessel borders, grade- 2 (moderate steatosis) - moderate diffuse increase in the fine echoes with slightly impaired visualization of the intrahepatic vessels and diaphragm, grade-3 (severe steatosis) - marked increase in the fine echoes with poor or no visualization of intrahepatic vessel borders, diaphragm and posterior portion of the right lobe of the liver. Statistical analysis was done by statistical package for social scientists (SPSS) version 
21. Data were expressed as mean, standard deviation (SD), percentage etc. Chi-square test $\left(\chi^{2}\right)$ was used for the comparison of qualitative data. Independent sample t-test was used for comparison between two groups. Results were considered statistically significant at $\mathrm{p}$ value $<0.05$.

\section{Results}

Among the 110 patients, 80 (72.7\%) had NAFLD and $56(50.9 \%)$ fulfilled criteria for metabolic syndrome, which was $70 \%$ of NAFLD $(56 / 80,70 \%)$ patients. Among the 56 NAFLD patients who had metabolic syndrome, $25 \%$ had all the components of metabolic syndrome and all the female subjects (32) with NAFLD had metabolic syndrome. Twenty one $(21 / 56,37.5 \%)$ of NAFLD patient with metabolic syndrome had hypertension and $16(28.6 \%), 26(46.4 \%)$ and $14(25 \%)$ had mild, moderate and severe form of NAFLD respectively. High TG, TC and LDL were present in $69.6 \%, 51.8 \%$ and $76.8 \%$ cases respectively and $85.7 \%$ had low HDL. Comparison of base-line characteristics of NAFLD patients with and without metabolic syndrome is shown in Table I.

\begin{tabular}{|c|c|c|c|}
\hline Characteristic & $\begin{array}{l}\text { NAFLD } \\
\text { with } \\
\text { metabolic } \\
\text { syndrome }\end{array}$ & $\begin{array}{l}\text { NAFLD } \\
\text { without } \\
\text { metabolic } \\
\text { syndrome }\end{array}$ & $\overline{\mathrm{p} \text { value }}$ \\
\hline Age (years) & $43.11 \pm 10.77$ & $44.13 \pm 11.56$ & 0.706 \\
\hline BMI (kg/m2) & $27.87 \pm 3.72$ & $24.17 \pm 2.75$ & 0.000 \\
\hline $\begin{array}{l}\text { Systolic BP } \\
(\mathrm{mm} \mathrm{Hg})\end{array}$ & $127.32 \pm 18.16$ & $126.46 \pm 16.25$ & 0.841 \\
\hline $\begin{array}{l}\text { Diastolic BP } \\
(\mathrm{mm} \mathrm{Hg})\end{array}$ & $80.71 \pm 10.11$ & $80.83 \pm 8.42$ & 0.960 \\
\hline WC (cm) & $94.01 \pm 8.67$ & $85.00 \pm 6.50$ & 0.000 \\
\hline WHR & $1.01 \pm 0.08$ & $0.95 \pm 0.05$ & 0.003 \\
\hline ALT (U/L) & $104.91 \pm 61.55$ & $92.83 \pm 31.30$ & 0.366 \\
\hline $\mathrm{FBG}(\mathrm{mmol} / \mathrm{L})$ & $11.91 \pm 4.15$ & $11.79 \pm 4.20$ & 0.910 \\
\hline TG (mg/dL) & $203.03 \pm 99.63$ & $184.50 \pm 108.01$ & 0.459 \\
\hline TC (mg/dL) & $203.35 \pm 52.36$ & $201.66 \pm 43.85$ & 0.890 \\
\hline $\mathrm{LDL}(\mathrm{mg} / \mathrm{dL})$ & $127.39 \pm 39.74$ & $137.18 \pm 41.49$ & 0.322 \\
\hline $\operatorname{HDL}(\mathrm{mg} / \mathrm{dL})$ & $36.05 \pm 8.32$ & $36.79 \pm 7.93$ & 0.714 \\
\hline
\end{tabular}

[WC $=$ Waist circumference, $\mathrm{WHR}=$ waist hip ratio $]$
All the patients were diabetic and a comparison of components of metabolic syndrome in patients with and without metabolic syndrome are presented in Table II.

Table II Comparison of components of metabolic syndrome in NAFLD patients with $(\mathrm{N}=56)$ and without metabolic syndrome $(\mathrm{N}=24)$

\begin{tabular}{cccc}
\hline Variables & NAFLD with & NAFLD & p \\
& metabolic & without & value \\
& syndrome (n-56) & metabolic & \\
& N (\%) & syndrome (n-56) & \\
& & N (\%) & \\
\hline
\end{tabular}

$\mathrm{BMI}\left(\mathrm{kg} / \mathrm{m}^{2}\right)$

$\begin{array}{lccc}18.5-24.9 & 7 & 15 & 0.000 \\ 25-29.9 & 30 & 7 & \\ =30 & 19 & 2 & \end{array}$

Systolic BP (mmHg)

$\begin{array}{cccc}<130 & 35 & 17 & 0.611 \\ =130 & 21 & 7 & \end{array}$

Diastolic BP (mmHg)

$\begin{array}{lccc}<85 & 37 & 17 & 0.797 \\ =85 & 19 & 7 & \\ \text { WC }(\mathrm{cm}) \text { (male) } & & & \\ <90 & 0 & 22 & 0.000 \\ =90 & 24 & & \\ \text { WC }(\mathrm{cm}) \text { (female) } & & 0 & --- \\ <80 & 0 & 0 & \\ =80 & 32 & & \\ \text { TG }(\mathrm{mg} / \mathrm{dL}) & & 13 & \\ <150 & 17 & 11 & \\ =150 & 39 & & \\ \text { HDL }(\mathrm{mg} / \mathrm{dL}) \text { (male) } & & 15 & \\ <40 & 19 & 9 & \\ =40 & 5 & & \end{array}$

\section{Discussion}

In this study, $70 \%$ of NAFLD subjects had metabolic syndrome according to the IDF criteria using AsianIndian standards for waist circumference. It was much higher than two studies done by Duseja A et al (50\%) and Uchil D et al (47.1\%). ${ }^{21,22}$ Among the NAFLD 
subjects with metabolic syndrome, $57.1 \%$ were female which was lower than that reported by Gaharwar R $(61.1 \%) .{ }^{23}$ Over two-thirds (71.4\%) of NAFLD subjects with metabolic syndrome had moderate to severe (grade 2 to 3 ) fatty liver which was lower than that reported by Gaharwar R (83.3\%). ${ }^{23}$ The mean age of NAFLD subjects with metabolic syndrome of present study was higher than that reported by Bajaj S et al. ${ }^{24}$ The BMI and WC of NAFLD subjects with metabolic syndrome was significantly higher than those of NAFLD subjects without metabolic syndrome in our study. Similar observation was reported by Gaharwar R. ${ }^{23}$ Hypertension was found in $37.5 \%$ of NAFLD subjects with metabolic syndrome which was lower than that reported by Bajaj S et al (48.72\%). ${ }^{24}$ In NAFLD subjects with metabolic syndrome, $69.6 \%$ had high TG which was significantly higher than findings of Uchil D et al $(43.6 \%)^{22}$ and $85.7 \%$ had low HDL levels which was lower than that described by Gaharwar R $(94.4 \%){ }^{23}$

The diagnosis of NAFLD was based only on USG imaging. The sensitivity of USG in detecting NAFLD may vary between $60 \%$ and $94 \%$ and the USG finding can be reported as normal in case of hepatic fibrosis. ${ }^{25}$ Magnetic resonance spectroscopy (MRS) can be used to confirm the grading of hepatic steatosis demonstrated by USG. ${ }^{26}$ The gold-standard technique for the diagnosis of NAFLD is liver biopsy. ${ }^{27}$ MRS or liver biopsy was neither feasible nor practical in such a cross-sectional study. Another limitation of our study was short duration of study period and small sample size.

In conclusion, seventy percent of newly diagnosed T2DM subjects with raised ALT and NAFLD had metabolic syndrome in this study. The components of metabolic syndrome were more prevalent in T2DM patients having NAFLD. Therefore, whenever these parameters are encountered in the clinical setting, patients should be evaluated for the presence of NAFLD. Early detection of NAFLD would modify the disease course and also play a role in modifying components of metabolic syndrome thus also benefit cardiovascular risk factors.

Conflicts of interest: Nothing to declare.

\section{References}

1. Neuschwander-Tetri BA, Caldwell S. Nonalcoholic steatohepatitis: summary of AASLD single topic conference. Hepatology 2003; 37: 1202-19.
2. Farrell GC, Wong VW, Chitturi S. NAFLD in Asia - as common and important as in the West. Nat Rev Gastroenterol Hepatol 2013; 10 (5): 307-18.

3. Younossi ZM, Koenig AB, Abdelatif D, Fazel Y, Henry L, Wymer M. Global Epidemiology of Non-Alcoholic Fatty Liver Disease-Meta-Analytic Assessment of Prevalence, Incidence and Outcomes. Hepatology 2016; 64 (1): 73-84.

4. Lonardo A, Bellentani S, Argo CK, Ballestri S, Byrne CD, Caldwell SH, et al. Epidemiological modifiers of nonalcoholic fatty liver disease: Focus on high-risk groups. Dig Liver Dis 2015; 47 (12): 997-1006.

5. Lonardo A, Sookoian S, Pirola CJ, Targher G. Non-alcoholic fatty liver disease and risk of cardiovascular disease. Metabolism 2016; 65 (8): 1136-50.

6. Targher G, Day CP, Bonora E. Risk of cardiovascular disease in patients with nonalcoholic fatty liver disease. N Engl J Med 2010; 363(14): 1341-50.

7. Privitera G, Spadaro L, Alagona C, Calanna S, Piro S, Rabuazzo AM, et al. Hepatic insulin resistance in NAFLD: relationship with markers of atherosclerosis and metabolic syndrome components. Acta Diabetol 2016; 53 (3): 449-59.

8. Al Rifai M, Silverman MG, Nasir K, Budoff MJ, Blankstein $\mathrm{R}$, Szklo M, et al. The association of nonalcoholic fatty liver disease, obesity, and metabolic syndrome, with systemic inflammation and subclinical atherosclerosis: the MultiEthnic Study of Atherosclerosis (MESA). Atherosclerosis 2015; 239 (2): 629-33.

9. Anstee QM, Targher G, Day CP. Progression of NAFLD to diabetes mellitus, cardiovascular disease or cirrhosis. Nat Rev Gastroenterol Hepatol 2013; 10 (6): 330-44.

10. Younossi ZM, Otgonsuren M, Venkatesan C, Mishra A. In patients with non-alcoholic fatty liver disease, metabolically abnormal individuals are at a higher risk for mortality while metabolically normal individuals are not. Metabolism 2013; 62 (3): 352-60.

11. Wong RJ, Ahmed A. Obesity and non-alcoholic fatty liver disease: Disparate associations among Asian populations. World J Hepatol 2014; 6 (5): 263-73.

12. Bertolotti M, Lonardo A, Mussi C, Baldelli E, Pellegrini E, Ballestri S, et al. Nonalcoholic fatty liver disease and aging: epidemiology to management. World J Gastroenterol 2014; 20 (39): 14185-204.

13. Sanyal AJ, Brunt EM, Kleiner DE, Kowdley KV, Chalasani $\mathrm{N}$, Lavine JE, et al. End points and clinical trial design for nonalcoholic steatohepatitis. Hepatology 2011; 54 (1): 344-53.

14. Miliæ S, Stimac D. Nonalcoholic fatty liver disease/ steatohepatitis: epidemiology, pathogenesis, clinical presentation and treatment. Dig Dis 2012; 30 (2): 158-62.

15. Ballestri S, Lonardo A, Romagnoli D, Carulli L, Losi L, Day $\mathrm{CP}$, et al. Ultrasonographic fatty liver indicator, a novel score 
which rules out NASH and is correlated with metabolic parameters in NAFLD. Liver Int 2012; 32 (8):1242-52.

16. Kwon YM, Oh SW, Hwang SS, Lee C, Kwon H, Chung GE, et al. Association of nonalcoholic fatty liver disease With components of metabolic syndrome according to body mass index in Korean adults. Am J Gastroenterol 2012; 107 (12):1852-58.

17. Vanni E, Bugianesi E, Kotronen A, De Minicis S, Yki-Jarvinen H, Svegliati-Baroni G. From the metabolic syndrome to NAFLD or vice versa? Dig Liver Dis 2010; 42 (5): 320-30.

18. Wong RJ, Cheung R, Ahmed A. Non-alcoholic steatohepatitis is the most rapidly growing indication for liver transplantation in patients with hepatocellular carcinoma in the US. Hepatology 2014; 59 (6): 2188-95.

19. Eckel RH, Alberti KG, Grundy SM, Zimmet PZ. The metabolic syndrome. Lancet 2010; 375 (9710): 181-83.

20. Welzel TM, Graubard BI, Zeuzem S, EI-Serag HB, Davila JA, McGlynn KA. Metabolic syndrome increases the risk of primary liver cancer in the United States: a study in the SEERMedicare database. Hepatology 2011; 54 (2): 463-71.

21. Duseja A, Das A, Das R, Dhiman RK, Chawla Y, Bhansali A, et al. The Clinicopathological Profile of Indian Patients with Nonalcoholic Fatty Liver Disease (NAFLD) is Different from that in theWest. Dig Dis Sci 2007; 52 (9): 2368-74.

22. Uchil D, Pipalia D, Chawla M, Patel R, Maniar S, Narayani et al. Non-Alcoholic Fatty Liver Disease (NAFLD) - The
Hepatic Component of Metabolic Syndrome. J Assoc Physicians India 2009; 57: 201-04.

23. Gaharwar R, Trikha S, Margekar SL, Jatav OP, Ganga PD. Study of clinical profile of patients of nonalcoholic fatty liver disease and its association with metabolic syndrome. J Assoc Physicians India 2015; 63 (1): 12-16.

24. Bajaj S, Nigam P, Luthra A, Pandey RM, Kondal D, Bhatt SP, et al. A case-control study on insulin resistance, metabolic covariates \& prediction score in non-alcoholic fatty liver disease. Indian J Med Res 2009; 129 (3): 285-92.

25. Fierbinteanu-Braticevici C, Dina I, Petrisor A, Tribus L, Negreanu L, Carstoiu C. Noninvasive investigations for nonalcoholic fatty liver disease and liver fibrosis. World $\mathrm{J}$ Gastroenterol 2010; 16 (38): 4784-91.

26. Williamson RM, Prince JF, Glancy S, Perry E, Nee LD, Hayes $\mathrm{PC}$, et al. Prevalence of and risk factors for hepatic steatosis and nonalcoholic fatty liver disease in people with type 2 diabetes: Edinburg type 2 Diabetes study. Diabetes Care 2011; 34 (5): 1139-44.

27. Chalasani N, Younossi Z, Lavine JE, Diehl AM, Brunt EM, Cusi K, et al. The diagnosis and management of nonalcoholic fatty liver disease: practice guideline by the American Association for the study of Liver Diseases, American College of Gastroenterology, and the American Gastroenterological Association. Hepatology 2012; 55 (6): 2005-23. 